\title{
Alteration of Cytokine Profiles in Uranium Miners Exposed to Long-Term Low Dose Ionizing Radiation
}

\author{
Kun Li, ${ }^{1}$ YiShui Chen, ${ }^{2}$ XiaoLiang Li, ${ }^{1}$ ShuJie Lei, ${ }^{1}$ QingFeng Chen, \\ JianXiang Liu, ${ }^{1}$ and QuanFu Sun ${ }^{1}$ \\ ${ }^{1}$ Key Laboratory of Radiological Protection and Nuclear Emergency, National Institute for Radiological Protection, \\ Chinese Center for Disease Control and Prevention, 2 Xinkang Street, Deshengmenwai, Xicheng District, Beijing 100088, China \\ ${ }^{2}$ Institute of Occupational Medicine of Jiangxi, 336 Yongwaizheng Street, Nanchang 330006, China \\ Correspondence should be addressed to QuanFu Sun; qfusun@gmail.com
}

Received 10 February 2014; Revised 13 April 2014; Accepted 13 April 2014; Published 29 April 2014

Academic Editor: Igor Belyakov

Copyright (C) 2014 Kun Li et al. This is an open access article distributed under the Creative Commons Attribution License, which permits unrestricted use, distribution, and reproduction in any medium, provided the original work is properly cited.

Objective. The aim of the study is to estimate the immune function through cytokine profiles in sera of uranium mines. Methods. Antibody arrays were used to detect 50 cytokines in sera of uranium miners. Miners who had continuously worked underground for $<5$ years were treated as control group and those who worked for $\geqslant 5$ years as experimental group. Results. Of 28 measurable cytokines, the release of IL- $1 \alpha$, IL-1RI, IL-15, IL-3, and IP-10 were significantly upregulated in the experimental group, and no cytokine was found significantly downregulated. Other proinflammatory cytokines such as IFN- $\gamma$, IL-10, IL-6, and TNF $\alpha$ levels were slightly upregulated in the experimental group. With adjustment to age, BMI, and cigarette smoking, IL-1 $\alpha$ and IL-3 levels increased significantly with underground time. Conclusion. Alteration of cytokine profiles in this study may indicate persistent inflammatory responses in uranium miners exposed to long-term low doses radiation.

\section{Introduction}

The immune-suppressing effect of high-dose radiation was clearly demonstrated and confirmed both in experimental and epidemiological studies $[1,2]$. The effects of low dose radiation (LDR) on the immune system, on the other hand, both stimulatory and suppressive effects, have been reported by estimating changes in cell numbers or by using a variety of functional assays [3-8]. The long-term impacts of low radiation dose on the immune functions in relation to human health are controversial and need to be evaluated [9-12]. As a representative occupational subgroup, uranium mine workers are exposed to internal radiation mainly caused by radon and its progeny and external radiation from gamma radiation. External radiation represents $28 \%$ of total dose for underground miners [13], and, in China, gamma radiation dose that underground miners received was about $4 \mathrm{mSv} /$ year based on the monitoring data gained in recent years [14]. It had been observed, in human populations inhabiting nearby a deactivated uranium mine, that immune functions were impaired by a significantly decreased NK and T lymphocytes counts [15]. However, the epidemiology study of uranium miners concerning immune function is scarce.

Cytokines, as the most important mediators by which cells of the immune system communicate, could be up- or downregulated by LDR [16-20]. However, the dysregulated expression of a special cytokine after irradiation does not sufficiently implicate its correlation with the pathogenesis [21]. Therefore, we estimated cytokine profiles to reflect the functional status of the immune system in this study. Furthermore, some cytokines in serum of healthy persons is generally low and no measurable level of cytokines was obtained using conventional ELISA (enzyme-linked immunosorbent assay) methods in preliminary experiments. Therefore, antibody microarray, having a higher sensitivity and greater detection range that promises to be a powerful tool for detecting multiple cytokine-expression levels simultaneously [22], was performed in this study to detect the relative expression of cytokine profiles. The aim of the present study is to estimate immune function with an emphasis on cytokine profiles in serum of workers from a uranium mine using antibody arrays. 


\section{Materials and Methods}

2.1. Participants. We studied subjects from a uranium mine in China and classified the miners into two groups based on continuous underground time because of the lack of dose of workers exposed to uranium. The control group included 21 male persons who continuously worked underground for $<5$ years (cumulative dose $<20 \mathrm{mSv}$, based on $4 \mathrm{mSv}$ per year), and the experiment group included 28 male miners continuously working underground for $\geqslant 5$ years $(\geqslant 20 \mathrm{mSv})$. On the day of blood sampling, all participants were subjected to medical examination and to routine haematological and biochemical tests for determination of their present health state, which revealed that they were basically healthy. This study obtained institutional approval from the human investigation committee and informed consents from participants.

2.2. Cytokines Analysis. Blood samples were collected from antecubital vein (between 7 a.m. and 9 a.m. before taking breakfast) of workers. Sera were obtained with blood centrifugation at 3600 r.p.m for $15 \mathrm{~min}$ and stored in a freezer at $4^{\circ} \mathrm{C}$. Fifty cytokine assay kits were custom made using Human G-Series Array (RayBiotech, Inc., Norcross, GA); one antibody array slide includes 14 subarrays, and each subarray contains 50 different cytokines in duplicated spots. The relative concentrations of cytokines were detected according to the manufacturer's instructions. Briefly, wells of the microarray glass slides were blocked in blocking buffer at room temperature for $30 \mathrm{~min}$ and subsequently incubated with $100 \mu \mathrm{L}$ of 2 -fold diluted sera overnight at $4^{\circ} \mathrm{C}$. Slides were washed in washing buffer and incubated with a biotin-conjugated anticytokines for $2 \mathrm{~h}$. After further washing, samples were incubated with $70 \mu \mathrm{L}$ of fluorescent dye conjugated per well in darkness for $2 \mathrm{~h}$. Centrifuge at $1000 \mathrm{rpm}$ for $3 \mathrm{~min}$ to remove water droplets. The images were captured using a LuxScan10K-A scanner. Spots signal intensities were imported into a RayBio antibody array tool for analysis automatically.

2.3. Statistical Analysis. The density of individual cytokines in all subjects was detected in duplicate. The average of the duplicate spots for each cytokine was normalized to the average of four positive controls on each array. The levels of cytokines in which the signal value of half the samples between two groups was above 200 were selected to further analysis. Group differences were analyzed with the SAM 3.00 algorithm. Any increase equal to or larger than 1.5 -fold or decrease equal to or lesser than 0.65 -fold in signal intensity for a single cytokine between the two groups is considered significant difference in expression. The significant difference is indicated by $q$ value. Thereafter, the relationship between continuous mining time and the concentrations of measurable cytokines were assessed in total group of subjects using a multivariate linear regression model performed with STATA software (Texas, USA).
TABLE 1: Twenty-eight cytokines measurable in serum of uranium miners.

\begin{tabular}{lcc}
\hline Cytokine & Fold change & $q$ value $(\%)$ \\
\hline IP-10 & 1.767 & $<0.05$ \\
IL-1 $\alpha$ & 1.712 & $<0.05$ \\
IL-1sRI & 1.650 & $<0.05$ \\
IL-3 & 1.622 & $<0.05$ \\
IL-15 & 1.586 & $<0.05$ \\
IL-2 & 1.427 & $<0.05$ \\
GM-CSF & 1.404 & $<0.05$ \\
IL-13 & 1.361 & $<0.05$ \\
TNF- $\beta$ & 1.357 & $<0.05$ \\
IL-2sR $\alpha$ & 1.315 & 3.1 \\
IL-7 & 1.288 & $<0.05$ \\
MCP-2 & 1.278 & 3.1 \\
IL-6 & 1.246 & 3.1 \\
ENA-78 & 1.237 & 3.1 \\
GRO & 1.232 & 3.1 \\
IL-10 & 1.229 & $<0.05$ \\
GCSF & 1.227 & 3.1 \\
IFN- $\gamma$ & 1.220 & 3.1 \\
TGF- $\beta$ & 1.213 & $<0.05$ \\
TNF- $\alpha$ & 1.172 & 3.1 \\
MIG & 1.153 & 3.1 \\
EGF & 1.085 & 3.1 \\
MIP-1 $\beta$ & 1.065 & 3.1 \\
LAP & 1.008 & 3.1 \\
IL-8 & 0.987 & $>5$ \\
RANTES & 0.966 & $>5$ \\
MCP-1 & 0.934 & \\
IL-6sR & 0.894 & \\
\hline & & \\
& &
\end{tabular}

\section{Results}

Of the 50 custom cytokines, 28 cytokines above 200 signal value were suggestive of measurable cytokines (Figure 1). Compared to the control group, miners in the exposed group showed increased secretion in IL- $\alpha$ by 1.712 fold, IL-1RI by 1.650 fold, IL-15 by 1.586 fold, IL-3 by 1.622 fold, and IP10 by 1.767 fold and there was no cytokines significantly downregulated. Besides, expression of other proinflammatory cytokines, such as IFN- $\gamma$, IL-10, IL-6, and TNF $\alpha$, was slightly upregulated in the exposed miners; the fold change is $1.220,1.229,1.246$, and 1.172, respectively (Table 1).

In our study, age distribution, body mass index (BMI), and cigarette smoking were similar to each other in the exposed and control group (Table 2). We used multiple regression analysis to explore the relationships between the secretion levels of upregulated cytokines and important covariates like age, mining time, body mass index, and cigarette smoking. The release of IL- $1 \alpha$ and IL-3 increased significantly with underground mining time with adjustment to age, BMI, and current smoking (Table 3). Conversely, age, $\mathrm{BMI}$, and current smoking were not significantly related with the release of IL- $1 \alpha$ and IL-3. 


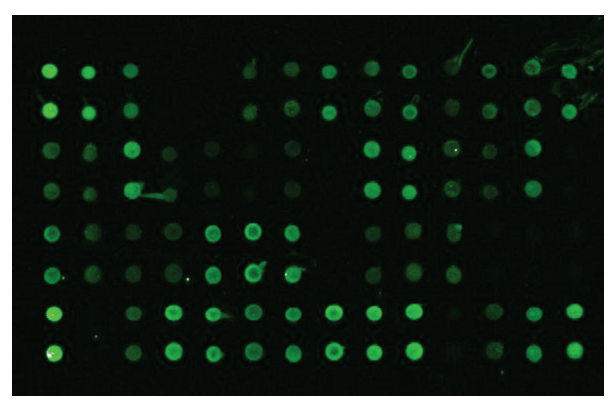

(a)

\begin{tabular}{|l|l|l|l|l|l|l|l|l|l|l|l|l|l|}
\hline Pos1 & Pos 2 & Pos3 & NEG & NEG & IFN- $\gamma$ & IL-1 $\alpha$ & IL-1 $\beta$ & IL-1 RI & IL-1 RII & IL-2 & IL-2R $\alpha$ & IL-3 & IL-4 \\
\hline Pos1 & Pos 2 & Pos3 & NEG & NEG & IFN- $\gamma$ & IL-1 $\alpha$ & IL-1 $\beta$ & IL-1 RI & IL-1 RII & IL-2 & IL-2R $\alpha$ & IL-3 & IL-4 \\
\hline IL-5 & IL-6 & IL-6sR & IL-7 & IL-8 & IL-9 & IL-10 & IL-11 & IL-12 p40 & IL-12 p70 & IL-13 & IL-15 & IL-16 & IL-17 \\
\hline IL-5 & IL-6 & IL-6sR & IL-7 & IL-8 & IL-9 & IL-10 & IL-11 & IL-12 p40 & IL-12 p70 & IL-13 & IL-15 & IL-16 & IL-17 \\
\hline IP-10 & GCSF & GM-CSF & MCSF & MCP-1 & MCP-2 & MCP-3 & TGF- $\alpha$ & TGF- $\beta$ & TNF- $\alpha$ & TNF- $\beta$ & TPO & VEGF & OSM \\
\hline IP-10 & GCSF & GM-CSF & MCSF & MCP-1 & MCP-2 & MCP-3 & TGF- $\alpha$ & TGF- $\beta$ & TNF- $\alpha$ & TNF- $\beta$ & TPO & VEGF & OSM \\
\hline RANTES & MIP-1 $\alpha$ & MIP-1 $\beta$ & LAP & OB & GRO & I-309 & ENA-78 & EGF & CD80 & MDC & MIG & SCF & POS2 \\
\hline RANTES & MIP-1 $\alpha$ & MIP-1 $\beta$ & LAP & OB & GRO & I-309 & ENA-78 & EGF & CD80 & MDC & MIG & SCF & POS2 \\
\hline
\end{tabular}

(b)

FIGURE 1: The cytokine profiles in sera of the subjects. (a) The comparative level of cytokines in sera of workers exposed to low dose irradiation were measured using Human G-Series Custom Array (RayBiotech, Inc., Norcross, USA) according to the manufacturer's suggestion. (b) The names of cytokines were list in the box.

TABLE 2: Characteristics of the study subjects.

\begin{tabular}{lcc}
\hline Characteristic & $\begin{array}{c}\text { Control group } \\
\text { working for }<5 \text { years } \\
(n=21) \\
\text { Number }(\%)\end{array}$ & $\begin{array}{c}\text { Experimental group } \\
\text { working for }>5 \text { years } \\
(n=28)\end{array}$ \\
\hline Age & $45.04 \pm 4.86$ & $47.36 \pm 2.91$ \\
BMI & $24.26 \pm 3.54$ & $23.64 \pm 2.93$ \\
Current smokers & $10(47.62)$ & $16(57.14)$ \\
\hline
\end{tabular}

TABLE 3: Multivariate models of the effects of underground time and age on IL- $1 \alpha$ and IL-3 expression.

\begin{tabular}{|c|c|c|}
\hline \multirow{2}{*}{ Variable } & IL- $1 \alpha$ & IL-3 \\
\hline & \multicolumn{2}{|c|}{$\begin{array}{l}\text { Percentage Increment } \\
\text { (95\% Confidence Interval) }\end{array}$} \\
\hline Time per 10 years & $30(9-51)$ & $38(6-70)$ \\
\hline Age per 10 years & $-27(-9-35)$ & $-78(-173-17)$ \\
\hline
\end{tabular}

\section{Discussion}

In this sera assay, immune responses of uranium miners were studied with the emphasis on cytokine-expression profiles. In our study, the levels of 28 cytokines measured in selected 50 cytokines showed that IL- $1 \alpha$, IL-1RI, IL-15, IL-3, and IP-10 levels were significantly upregulated in miners working for more than 5 years and there was no significantly downregulated cytokines between the two groups. With adjustment to age,
BMI, and current smoking, IL-1 $\alpha$ and IL-3 levels increased significantly with underground time.

The main biological activity of IL-1 is the stimulation of T-helper cells, which are induced to secrete IL-2 and to express IL- 2 receptors. IL- $1 \alpha$ may be a pathogenetic factor in the complex processes leading to vascular occlusion and an important in situ indicator of and a potential participant in vascular injury [23]. In this study, IL- $1 \alpha$ concentration in sera of miners working underground for more than 5 years was significantly higher than those for lesser than 5 years, indicating the inflammatory response occurring with long-term exposure to LDR. Moreover, the linear relationship between the underground time and the level of IL- $1 \alpha$ in sera of miners was revealed as a statistically significant positive correlation, implying that the inflammatory production could be attributed to long-term LDR. IL-1 had been reported to be a differentiation- and maturation-inducing agent for a variety of cells and also can serve as a signal that initiates radioprotective events in vivo [24, 25].

IL-3 is secreted by basophils and activated T cells to support the growth and differentiation of $\mathrm{T}$ cells from the bone marrow in an immune response and stimulates the differentiation of multipotent hematopoietic stem cells into myeloid progenitor cells. Elevation of IL-3 with underground time in miners working underground more than 5 years indicated the hormesis effect on hematopoietic system and activation of immune responses after chronic LDR. This result was similar to the study about stimulating effect of 
mice exposed to chronic low dose $\gamma$-irradiation $(0.7 \mathrm{mGy} / \mathrm{h}$ for 11.9 days to reach a total dose of $0.2 \mathrm{~Gy}$ ) on bone marrow hematopoietic progenitor cell proliferation and peripheral blood mobilization [26].

IFN- $\gamma$, IL-10, IL- 6 , and TNF- $\alpha$ coordinate the inflammatory response. In the present study, all these cytokines levels increased slightly but not significantly with underground time. Taking the results mentioned above, our study provided further evidence of persistent inflammatory response in persons exposed to LDR. Inflammatory cytokines expression in our results were consistent with the study of atomic bomb survivors, in which IFN- $\gamma$, IL-10, IL-6, and TNF- $\alpha$ increased expression providing evidence of persistent inflammatory responses in atomic bomb survivors more than 50 years after radiation exposure [15].

From cytokine profiles expressed in this study, we concluded that uranium miners receiving more than $20 \mathrm{mSv}$ per year produced the persistent inflammatory responses. There is evidence that short-term low doses irradiation can induce anti-inflammatory effects through the secretion of modulatory cytokines. Inflammatory cytokines IL- $1 \beta$ and TNF- $\alpha$ releases were reduced in peritoneal macrophages of $\mathrm{Balb} / \mathrm{c}$ mice responding to exposure of 0.5 or $0.7 \mathrm{~Gy}$ of ionizing irradiation (X-ray) [27]. Meanwhile, low/moderate doses (0.5 Gy or $1.0 \mathrm{~Gy}$ ) exposure is clinically used to treat benign inflammatory diseases and is therefore capable of downregulating inflammation $[28,29]$. However, in our study, it seems to suggest that inflammatory responses occurred after long-term exposure to low dose ionizing radiation and the mechanism between them is an area of current research. In addition, all the people we surveyed are healthy people and the concentrations of IL- $1 \alpha$ and IL-3 are pretty low in normal serum, so we could not quantity the levels in this study. For further study, it appears necessary to ensure an adequate study and control population and to get larger sample sizes and verify the cytokines expression, which may lead to significant progress in our understanding of the effects of chronic, low dose radiation exposure on immune functions.

\section{Conclusion}

Our study provides the first evidence to show cytokine profiles in sera of uranium miners and explore immune function after long-term low dose of ionizing radiation. We hypothesize that modification of cytokine production may indicate persistent inflammatory responses in uranium miners working underground for more than 5 years and cumulative dose is about $20 \mathrm{mSv}$. The emphasis of our next work is to ensure an adequate population to get large sample sizes and verify the cytokines expression in human populations exposed to long-term low dose of ionizing radiation.

\section{Conflict of Interests}

The authors declare that there is no conflict of interests regarding the publication of this paper.

\section{References}

[1] N. P. Harrington, K. A. Chambers, W. M. Ross, and L. G. Filion, "Radiation damage and immune suppression in splenic mononuclear cell populations," Clinical and Experimental Immunology, vol. 107, no. 2, pp. 417-424, 1997.

[2] M. Akiyama, "Late effects of radiation on the human immune system: an overview of immune response among the atomicbomb survivors," International Journal of Radiation Biology, vol. 68, no. 5, pp. 497-508, 1995.

[3] S. Z. Liu, S. Z. Jin, X. D. Liu, and Y. M. Sun, "Role of CD28/B7 costimulation and IL-12/IL-10 interaction in the radiationinduced immune changes," BMC Immunology, vol. 2, no. 1, p. 8, 2001.

[4] S. Kojima, S. Matsumori, H. Ishida, and K. Yamaoka, "Possible role of elevation of glutathione in the acquisition of enhanced proliferation of mouse splenocytes exposed to small-dose $\gamma$ rays," International Journal of Radiation Biology, vol. 76, no. 12, pp. 1641-1647, 2000.

[5] S. Z. Liu, Z. B. Han, and W. H. Liu, "Changes in lymphocyte reactivity to modulatory factors following low dose ionizing radiation," Biomedical and Environmental Sciences, vol. 7, no. 2, pp. 130-135, 1994.

[6] A. Shigematsu, Y. Adachi, N. Koike-Kiriyama et al., "Effects of low-dose irradiation on enhancement of immunity by dendritic cells," Journal of Radiation Research, vol. 48, no. 1, pp. 51-55, 2007.

[7] A. S. Yagunov, S. V. Tokalov, and A. B. Chukhlovin, "Animal studies of residual hematopoietic and immune system injury from low dose/low dose rate radiation and heavy metals," AFFRI Contract Report 98-3, Armed Forces Radiobiology Research Institute, Bethesda, Md, USA, 1998.

[8] A. A. Yarilin, I. M. Belyakov, O. I. Kusmenok et al., "Late T cell deficiency in victims of the Chernobyl radiation accident: possible mechanisms of induction," International Journal of Radiation Biology, vol. 63, no. 4, pp. 519-528, 1993.

[9] A. Safwat, "The immunobiology of low-dose total-body irradiation: More questions than answers," Radiation Research, vol. 153, no. 5 I, pp. 599-604, 2000.

[10] A. Godekmerdan, M. Ozden, A. Ayar, M. Ferit Gursu, A. Tevfik Ozan, and S. Serhatlioglu, "Diminished cellular and humoral immunity in workers occupationally exposed to low levels of ionizing radiation," Archives of Medical Research, vol. 35, no. 4, pp. 324-328, 2004.

[11] Y. Kusunoki, M. Yamaoka, Y. Kubo et al., "T-cell immunosenescence and inflammatory response in atomic bomb survivors," Radiation Research, vol. 174, pp. 870-876, 2010.

[12] O. Kuzmenok, M. Potapnev, S. Potapova et al., "Late effects of the Chernobyl radiation accident on T cell-mediated immunity in cleanup workers," Radiation Research, vol. 159, no. 1, pp. 109116, 2003.

[13] Sources and Effects of Ionizing Radiation, United Nations Scientific Committee on the Effects of Atomic Radiation, 1993.

[14] Z. Q. Pan and S. L. Liu, Radiation Level in China, China Atomic Energy Publishing and Media Co., Ltd, Beijing, China, 1st edition, 2011.

[15] J. Lourenco, R. Pereira, F. Pinto et al., "Biomonitoring a human population inhabiting nearby a deactivated uranium mine," Toxicology, vol. 305, pp. 89-98, 2013.

[16] T. Hayashi, Y. Morishita, Y. Kubo et al., "Long-term effects of radiation dose on inflammatory markers in atomic bomb 
survivors," The American Journal of Medicine, vol. 118, no. 1, pp. 83-86, 2005.

[17] M. Attar, Y. M. Kondolousy, and N. Khansari, "Effect of high dose natural ionizing radiation on the immune system of the exposed residents of Ramsar Town, Iran," Iranian Journal of Allergy, Asthma and Immunology, vol. 6, no. 2, pp. 73-78, 2007.

[18] E. N. Bogdándi, A. Balogh, N. Felgyinszki et al., "Effects of lowdose radiation on the immune system of mice after total-body irradiation," Radiation Research, vol. 174, no. 4, pp. 480-489, 2010.

[19] V. Gazin, S. Kerdine, G. Grillon, M. Pallardy, and H. Raoul, "Uranium induces TNF $\alpha$ secretion and MAPK activation in a rat alveolar macrophage cell line," Toxicology and Applied Pharmacology, vol. 194, no. 1, pp. 49-59, 2004.

[20] B. Wan, J. T. Fleming, T. W. Schultz, and G. S. Sayler, "In vitro immune toxicity of depleted uranium: effects on murine macrophages, CD4+ T cells, and gene expression profiles," Environmental Health Perspectives, vol. 114, no. 1, pp. 85-91, 2006.

[21] D. Schaue, E. L. Kachikwu, and W. H. McBride, "Cytokines in radiobiological responses: a review," Radiation Research, vol. 178, pp. 505-523, 2012.

[22] B. B. Haab, "Methods and applications of antibody microarrays in cancer research," Proteomics, vol. 3, no. 11, pp. 2116-2122, 2003.

[23] J. I. Brody, N. J. Pickering, D. M. Capuzzi, G. B. Fink, C. A. Can, and F. Gomez, "Interleukin- $1 \alpha$ as a factor in occlusive vascular disease," The American Journal of Clinical Pathology, vol. 97, no. 1, pp. 8-13, 1992.

[24] R. N. Shen, N. B. Hornback, H. Shidnia, B. Wu, L. Lu, and H. E. Broxmeyer, "Whole body hyperthermia: a potent radioprotector in vivo," International Journal of Radiation Oncology Biology Physics, vol. 20, no. 3, pp. 525-530, 1991.

[25] R. Neta, S. Douches, and J. J. Oppenheim, "Interleukin 1 is a radioprotector," Journal of Immunology, vol. 136, no. 7, pp. 24832485, 1986.

[26] S. C. Shin, K. M. Lee, Y. M. Kang et al., "Alteration of cytokine profiles in mice exposed to chronic low-dose ionizing radiation," Biochemical and Biophysical Research Communications, vol. 397, no. 4, pp. 644-649, 2010.

[27] B. Frischholz, R. Wunderlich, P. F. Ruhle et al., "Reduced secretion of the inflammatory cytokine IL-1beta by stimulated peritoneal macrophages of radiosensitive $\mathrm{Balb} / \mathrm{c}$ mice after exposure to 0.5 or 0.7 Gy of ionizing radiation," Autoimmunity, vol. 46, pp. 323-328, 2013.

[28] M. Arenas, S. Sabater, V. Hernández et al., "Anti-inflammatory effects of low-dose radiotherapy," Strahlentherapie und Onkologie, vol. 188, no. 11, pp. 975-981, 2012.

[29] F. Rödel, L. Keilholz, M. Herrmann, R. Sauer, and G. Hildebrandt, "Radiobiological mechanisms in inflammatory diseases of low-dose radiation therapy," International Journal of Radiation Biology, vol. 83, no. 6, pp. 357-366, 2007. 


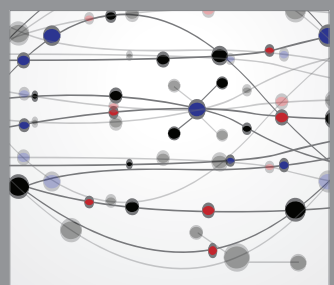

The Scientific World Journal
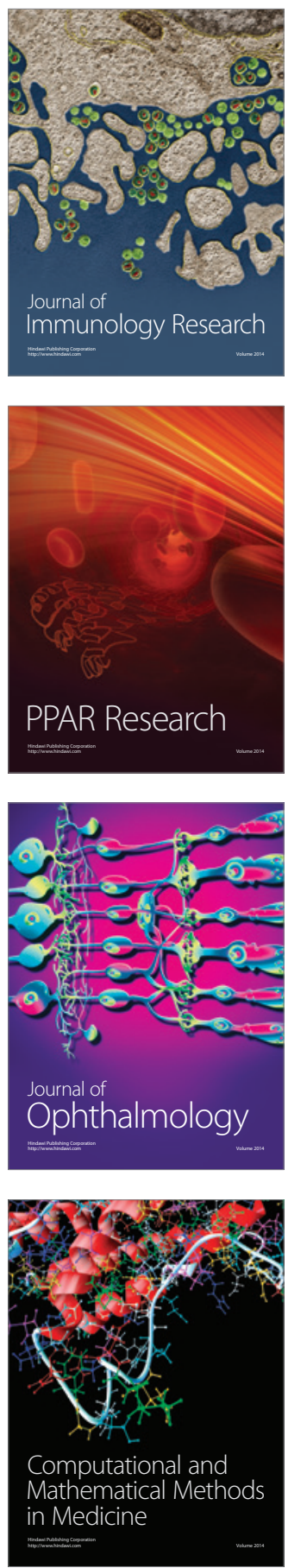

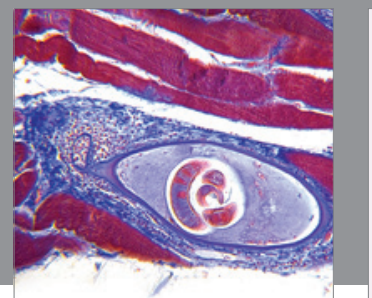

Gastroenterology

Research and Practice
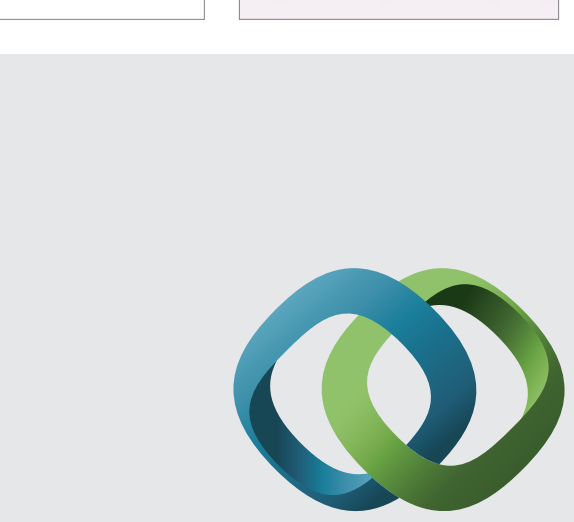

\section{Hindawi}

Submit your manuscripts at

http://www.hindawi.com
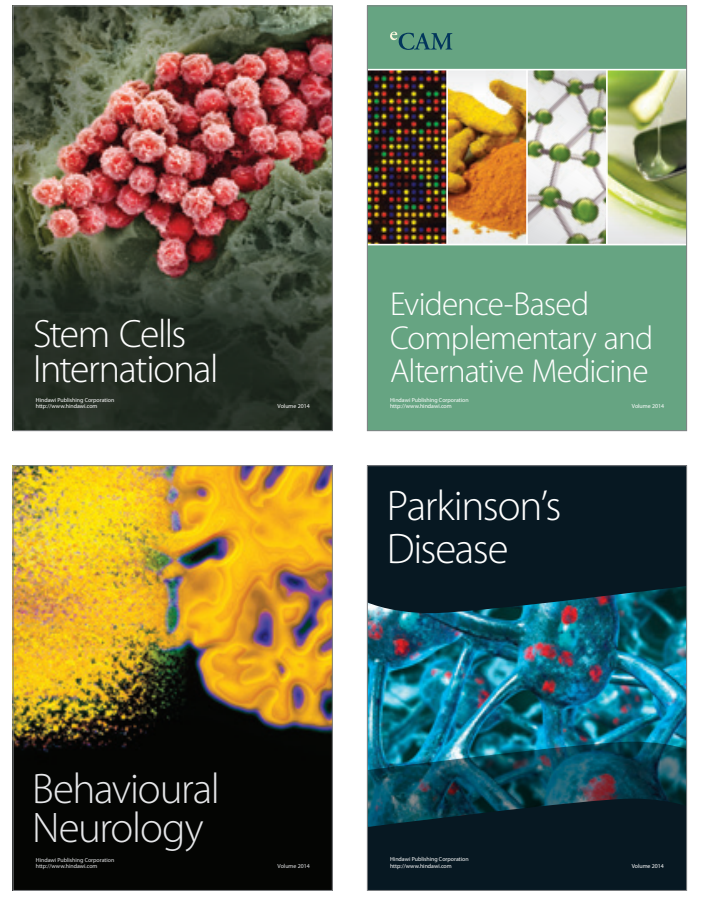
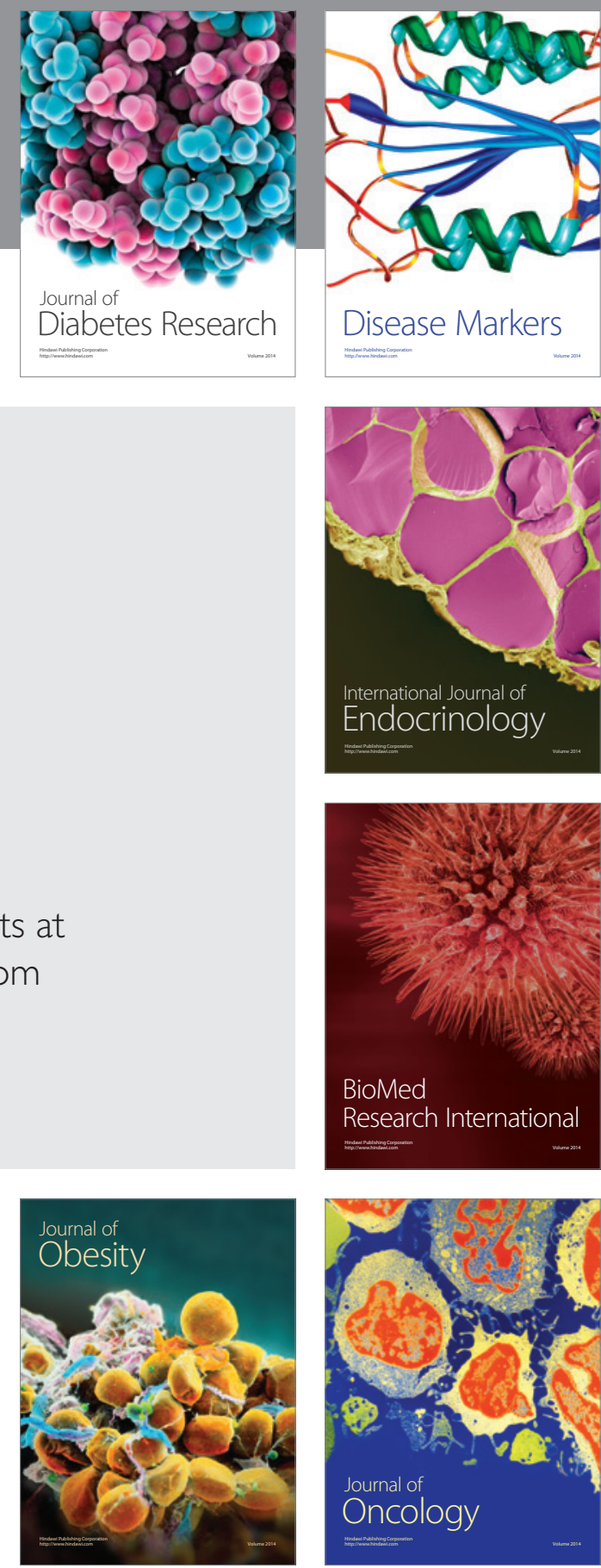

Disease Markers
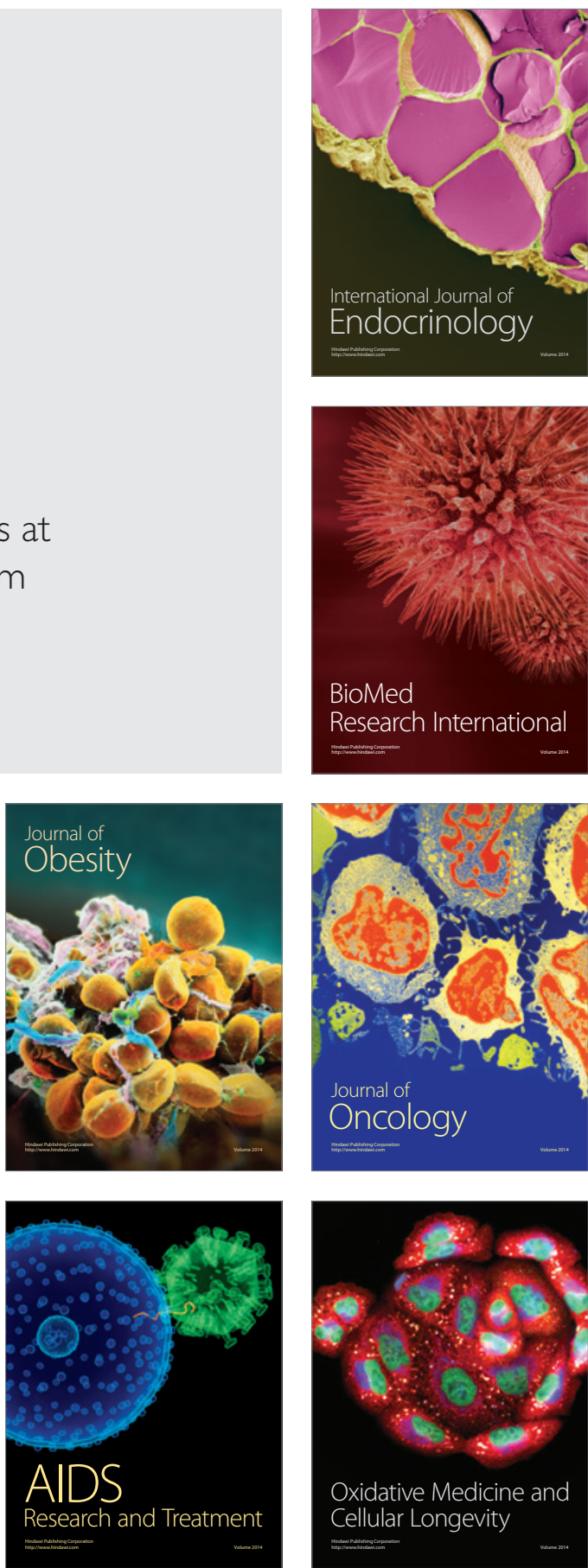